This item was submitted to Loughborough's Research Repository by the author.

Items in Figshare are protected by copyright, with all rights reserved, unless otherwise indicated.

\title{
An exploration of low-fidelity prototyping methods for augmented and virtual reality
}

PLEASE CITE THE PUBLISHED VERSION

https://doi.org/10.1007/978-3-030-49760-6_33

PUBLISHER

Springer

VERSION

AM (Accepted Manuscript)

PUBLISHER STATEMENT

The final authenticated version is available online at https://doi.org/10.1007/978-3-030-49760-6_33.

LICENCE

CC BY-NC-ND 4.0

\section{REPOSITORY RECORD}

Maguire, Martin. 2020. "An Exploration of Low-fidelity Prototyping Methods for Augmented and Virtual Reality". Loughborough University. https://hdl.handle.net/2134/11904909.v1. 


\title{
An Exploration of Low-Fidelity Prototyping Methods for Augmented and Virtual Reality
}

\author{
Martin Maguire \\ School of Design and Creative Arts \\ Loughborough University \\ Leicestershire, LE11 3TU, UK \\ m.c.maguire@lboro.ac.uk
}

\begin{abstract}
Low-fidelity prototyping is well-established method of developing concepts for traditional two-dimensional user interfaces. This paper considers the techniques and methods that can be used for simulating and early testing of augmented and virtual reality applications. It covers techniques such as body-storming, storyboarding, and mocking up prototypes using a variety of materials such as: sheets of paper, cardboard, sticky tape, straws, pin-boards, Lego bricks, etc. It describes the role of each method within the design process and provides practical advice for its application. The paper draws upon two student workshops that were organized to teach and practice several of these techniques for the design of augmented reality and virtual reality prototypes. Feedback from the participants is reported.
\end{abstract}

Keywords: Virtual reality, Augmented reality, Low-Fidelity Prototyping, Rapid Prototyping, User-centred design, User Interface Design, User Experience Design.

\section{Introduction}

Augmented reality (AR) is an experience where users see and interact with the real world while digital content is added to it. Typically, the real world is presented on a mobile device through the device's camera. Pokemon Go is a famous example of this application where the player searches for small virtual creatures that appear overlaid on the real scene. A different way to experience augmented reality is through an AR headset, such as Google Glass, where digital content is displayed on a very small screen in front of the user's eye. Applications of augmented reality can include entertainment (i.e. video games), enhanced shopping experiences, and head up displays for drivers and pilots.

Virtual reality (VR) immerses users in a completely virtual environment that is generated by a computer. Advanced VR experiences provide freedom of movement so that users can move in a digital environment and hear sounds. Moreover, special hand controllers can be used to enhance VR experiences. Applications of virtual reality also include entertainment (i.e. video games) and education (school teaching, medical training or military training). It is believed that the participants of such training not only learn faster, but also retain new information longer and are more motivated and attentive during classes.

Low-fidelity prototyping is a well-established method of developing concepts for traditional two-dimensional user interfaces [1]. This paper considers the techniques and methods that can be used for simulating and early testing of augmented and virtual reality. It also reports the feedback from two master's student workshops organized to teach and practice different rapid prototyping methods for AR and VR. 


\section{User research}

The first stage in a user-centered design process is user research [2]. This involves identifying the target audience, understanding the user's context, and identifying their needs. Achieving empathy with the user is a key aspect of these activities. The research process is completed with a definition of the specific problem to be addressed by the design team. In deciding whether to employ AR or VR technology, it is worth considering the pros and cons of each (Table 1):

Table 1. Advantages and disadvantages of augmented reality and virtual reality

\begin{tabular}{|c|c|c|}
\hline & Advantages & Disadvantages \\
\hline Augmented reality & $\begin{array}{l}\text { Real world experience can be en- } \\
\text { hanced with additional infor- } \\
\text { mation e.g. objects appearing } \\
\text { when reading a book, or shop } \\
\text { names popping up when viewing a } \\
\text { town high street. } \\
\text { Possible to visualize the object in } \\
\text { a more effective form e.g. item of } \\
\text { clothing being worn before mak- } \\
\text { ing an actual purchase. } \\
\text { Can be applied to parts of training } \\
\text { programs so that overall produc- } \\
\text { tivity is increased. } \\
\text { Can reduce risk when performing } \\
\text { an activity e.g. a surgical opera- } \\
\text { tion, by giving the user improved } \\
\text { sensory perception. } \\
\text { Can provide a framework so that } \\
\text { users interact in a synchronized } \\
\text { manner e.g. to enhance teamwork. }\end{array}$ & $\begin{array}{l}\text { Can diminish real world reality } \\
\text { or lead to people becoming more } \\
\text { dependent on devices which may } \\
\text { cause health-related issues. } \\
\text { Open architecture of the aug- } \\
\text { mented reality applications } \\
\text { leaves it vulnerable to cyber-at- } \\
\text { tacks and threats. } \\
\text { Potentially expensive to develop } \\
\text { an AR based system. } \\
\text { Maintenance of an AR system } \\
\text { can also be expensive unless de- } \\
\text { signed to be easily updated or } \\
\text { customised. }\end{array}$ \\
\hline Virtual reality & $\begin{array}{l}\text { Immersive - can create involving } \\
\text { immersive experiences. } \\
\text { Interactive nature means it im- } \\
\text { proves retention and recall. } \\
\text { Can simulate a dangerous environ- } \\
\text { ment for training purposes. } \\
\text { Can facilitate a meeting situation } \\
\text { in a realistic way saving time and } \\
\text { money. } \\
\text { Simplifies complex problems or } \\
\text { situations. } \\
\text { Suitable for different learning } \\
\text { styles. }\end{array}$ & $\begin{array}{l}\text { Can be expensive to produce or } \\
\text { update. } \\
\text { Health effects - can lead to spa- } \\
\text { tial awareness, dizziness, disori- } \\
\text { entation, and nausea. } \\
\text { If a person relies more on virtual } \\
\text { reality for social interactions, can } \\
\text { ultimately lead to depression and } \\
\text { disassociation. }\end{array}$ \\
\hline
\end{tabular}




\section{$3 \quad$ Bodystorming}

Bodystorming is a technique used to quickly generate and evaluate design ideas that are vague or too early stage to prototype [3, 4]. The design team members act out scenes imagined in an AR or VR application. The purpose is to ideate quickly and efficiently by encouraging participants to think spatially.

If the application is AR, then the method can use a single cardboard frame to act as a window to the real world. As the user walks around, others in the team can point to items and voice the information that is presented as the user approaches it. During this process, there can be discussion as to what information would be useful to present.

If the application is VR, a similar effect can be achieved by asking one person (the user) to put on a makeshift headset e.g. a simple box with a viewing hole [5]. This helps to build user empathy, allowing the design team to understand how the user feels when they have a limited field of view. A second person then pretends to be the object the user is interacting with and can respond to the user's gestures accordingly. Alternatively, they can manipulate objects (imagined or made of cardboard or paper) that the user indicates. The pair act out what the user's task or mission including what they see and hear, and their actions through gestures and voice. This helps the designers to see users to interact with menu systems and which interactions are essential and intuitive, and which are not. It will also help understand how to improve the clarity of the experience from the user's perspective.

\section{Storyboards}

Storyboards are an effective tool for capturing and conveying ideas and concepts for a proposed experience [3]. A storyboard is a sequence of sketched images to show a set of scenes that a user might follow whether in AR or VR. The method, commonly used in the entertainment industry, helps to convey both the overall flow of an experience (at low fidelities) as well as the aesthetic look and feel (at high fidelities). Understanding the fidelity needs of your storyboard is key to gathering the right kind of feedback and avoiding counter-productive discussions.

Low-fidelity storyboards are appropriate for quick discussions, especially when conveying high-level ideas. These can be as simple as stick-figure drawings and primitive shapes to denote virtual elements in a scene or the proximity of interactive components (both physical and virtual). High-fidelity storyboards are useful when bringing in new stakeholders or combining insights from a bodystorming session with the proposed aesthetic direction of the experience. Generally, it is helpful to include captions to explain the action within each scene and possibly speech or thought bubbles (as in a comic-book) to indicate speech interaction or thought processes.

As the design develops, it may be useful to sketch out the story in third person and first person [4]. Sketching in third person allows the design team to view the experience at a distance and can help describe the big picture components of the experience being created. Sketching in first person allows the team to understand the field of view of the device and allows the team to make sure that they are including everything that is needed in the user's line of vision. Both perspectives allow each element of your experience to be laid out in a thoughtful way, especially if designing an application allowing 360 movement. 


\section{$5 \quad$ Testing scenarios with low-fidelity physical prototypes}

The next part of the UX process is to envision the design using low-fidelity prototyping methods so that design team members can share the concept and allow it to be tested with users. Using the ideas developing during bodystorming, scenarios can be developed to walk through. This involves staging how a user would move through the experience and use physical props [3]. This allows participants to not only experience the thinking through the perspective of the user but allow outside observers to see how events play out.

It may also be useful to include a wider audience of team members or stakeholders who are able to provide specific 'expert' feedback. For example, when exploring an augmented or virtual experience designed for hospitals, acting out the team's thinking to a medical professional to show how the experience might unfold and can provide invaluable feedback. Having a technical developer present might also give them heads up on the kinds of challenges they might face in creating the application or trading off visual quality for performance or deciding what assets are needed for application development.

For an AR application, a suitable way to develop a low-fidelity prototype is to create a cardboard frame to represent the mobile device, while objects such as information labels or miniature figures can be placed behind it to provide the augmented elements. The user can hold the frame and view the real world through it (although this may be a hand drawn scene) while the support team hold up the augmentations attached to straws or sticks or attach Post-Its to real world objects as the user views them. Another form of Augmented reality relating to retail clothes shopping is to use a projector to show an image of the augmented mirror which, with pre-prepared images can show the customer wearing their chosen garment as a digital representation (see Fig. 1).
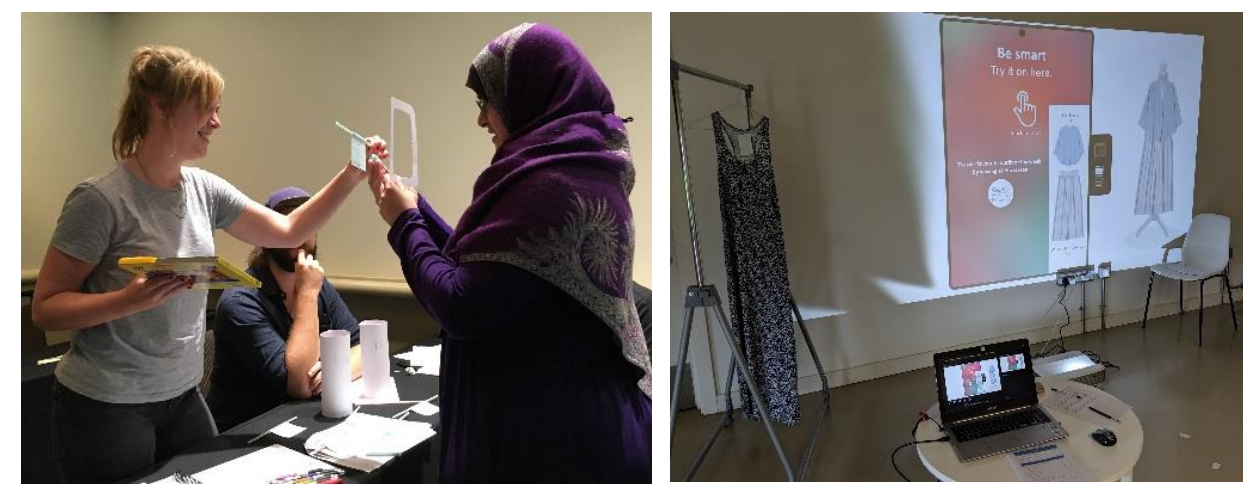

Fig 1. Augmented reality prototyping (a) using frame and post-its, and (b) mock-up of mark mirror using short-throw projector

In one study, the authors developed an idea for an app for people watching a rugby match [5]. While waiting for a spot kick to be taken on the field, the user could try and score themselves by viewing the real posts through the app and swiping a digital ball on screen. A physical prototype of the AR design was created and tested using a cardboard frame for viewing a model of the rugby posts, and flicking a cardboard ball, mounted on the frame, over them. 
For VR, it is possible to create an impression of immersion by projecting large images onto a wall or perhaps by setting up a sequence of display boards with a large sheet of paper displayed on each. If the boards are set up in fanfold fashion, this could simulate a sequence of VR locations. However, a more effective simulation could possibly be achieved by drawing an image on a paper template that is distorted similar to a projection of the world map. If photographed and uploaded to a suitable online tool and viewed on a mobile phone a $3 \mathrm{D}$ simulation is created allowing swiping motions on screen to explore the space. This can be enhanced further if the image is displayed as two images and viewed using a VR viewing headset in which a mobile phone can be inserted e.g. Google Cardboard. A walkie-talkie can be employed to simulate speech interaction, or a speaker nearby can be used to simulate sound.

Consideration of should be given for the input device that will be used within the application. Virtual reality systems with three degrees of freedom (3DOF) allow input by pointing and activation without letting the user reach out and interact with objects. Immersive VR experiences with six degrees of freedom (6DoF) add the ability to reach out and interact with objects in a 3D space. Tracking the user's fingers e.g. if wearing a data glove, allows for more control and flexibility e.g. to let go of the controller without it falling from the user's hand. The characteristics of the input device need to be included within the prototype. While the device may have constraints, the design should try to look for creative solutions within them, while also playing to a device's strengths.

\section{$6 \quad$ Creating digital prototypes}

Currently there are few easy to use prototyping tools for VR and AR, so it can take a lot of effort to create rapid digital prototypes for use within an iterative user-centred design cycle. Tools such as Google Expeditions can be used to create virtual experiences using a collection of $360^{\circ}$ scenes and $3 \mathrm{D}$ objects. The ease with which such tools can be used means that they can be used for low-fidelity prototyping. Digital prototyping in $2 \mathrm{D}$ useful for determining flow.

Creating a clickable prototype for either AR or VR in an app like Marvel App makes it more realistic [6]. While bodystorming helps to design user feelings, a clickable version helps to design for usability. The elements that the user can interact with can be equivalent to the touchpoints available in the design. When there is audio or text, this can be written out in the window. Even if this clutters the window, this is okay since the aim is to make the user experience and flow clear and planning for all the different answers to the "what if" questions that the design team have been working with. The $2 \mathrm{D}$ prototype serves as a roadmap for the developers to follow and lessens the chance that there will be major mistakes or communication errors.

Multimedia prototyping may use a mixture of digital and physical elements to test and validate design solutions for interacting with menu systems in AR or VR in a way that is interactive, immersive, and easy for users to observe [6]. One relatively easy way to create a series of 3D scenes that a user can explore is to create a series of images in Microsoft Paint 3D and then import them into PowerPoint. Another technique is to create a cardboard model of virtual scene and to place a $360^{\circ}$ camera within it. A still image taken with the camera will provide an all-round scene while a video taken on small figure moving around the scene can show interactions. The camera can also be moved around to show the layout of the virtual environment. 
Other tools such as Google Expeditions can be used to create virtual experiences using a collection of $360^{\circ}$ scenes and $3 \mathrm{D}$ objects. The ease with which such tools can be used means that they can be used for low-fidelity prototyping. When 3D environments need to be produced in higher fidelity, then specialist tools such as Unity are needed. This can take a lot of effort for easy integration into an iterative user-centred design cycle, although the creation, beforehand, of 3D assets for the developer can speed up the production time.

\section{$7 \quad$ Design principles}

General design principles such as those produced by Don Norman [7] are just relevant to AR and VR applications as to traditional interfaces. Table 2 lists Norman's six principles and their interpretation for AR and VR which should be followed when designing the prototype application:

Table 2. Norman's design principles applied to AR and VR

\begin{tabular}{|c|c|c|}
\hline Design principle & Augmented reality & Virtual reality \\
\hline Visibility & $\begin{array}{l}\text { Augmented elements such as la- } \\
\text { bels, text boxes and highlighting } \\
\text { should be clear and readable on the } \\
\text { device on which the AR applica- } \\
\text { tion is running at a normal viewing } \\
\text { distance. It should be clear what el- } \\
\text { ements the annotations relate to. }\end{array}$ & $\begin{array}{l}\text { Virtual elements should be clear } \\
\text { and visible to the user, enabling } \\
\text { them to interact with them easily. } \\
\text { Try to avoid using big text blocks } \\
\text { and highly detailed UI elements. } \\
\text { Consider what is the optimal dis- } \\
\text { tance that the VR screens were in- } \\
\text { tended to be viewed from which } \\
\text { will inform the size of the screen in } \\
\text { addition to the size and density of } \\
\text { the content therein [8]. Having a } \\
\text { way to enlarge text is helpful for } \\
\text { people with reduced vision. }\end{array}$ \\
\hline Feedback & $\begin{array}{l}\text { When the user selects an item to } \\
\text { manipulate in AR, it should be } \\
\text { clear that it has been selected with } \\
\text { suitable feedback. The result of the } \\
\text { action e.g. choosing an ornament } \\
\text { from an online shop for viewing in } \\
\text { situ, should be clear. }\end{array}$ & $\begin{array}{l}\text { When the user selects an item or } \\
\text { location in the virtual world, the } \\
\text { selection should be clear and the } \\
\text { result of the action performed on } \\
\text { the object should also be evident. }\end{array}$ \\
\hline Constraints & $\begin{array}{l}\text { Constraints is about limiting the } \\
\text { range of interaction possibilities } \\
\text { for the user to simplify the inter- } \\
\text { face and guide the user to the ap- } \\
\text { propriate next action. It should be } \\
\text { made clear in the AR environment } \\
\text { which objects can be selected. }\end{array}$ & $\begin{array}{l}\text { In the virtual world, while it may } \\
\text { seem that the user can select any } \\
\text { item, it may be helpful to provide } \\
\text { some guidance as to what can be } \\
\text { selected. This can be achieved } \\
\text { through highlighting of items, } \\
\text { showing they are selectable, as the } \\
\text { user moves a pointer around. }\end{array}$ \\
\hline Mapping & $\begin{array}{l}\text { Mapping is about having a clear re- } \\
\text { lationship between controls and the } \\
\text { effect they have on the world. Ac- } \\
\text { tions such as swiping on the device } \\
\text { to perform an action should match } \\
\text { user expectations e.g. swiping } \\
\text { speed and direction should be }\end{array}$ & $\begin{array}{l}\text { In VR the user will have a control- } \\
\text { ler to move around. Clicking the } \\
\text { pointer to indicate relocation is } \\
\text { useful for larger movements } \\
\text { around a space e.g. a museum. Us- } \\
\text { ing a joystick type action may be } \\
\text { easier for smaller movements e.g. }\end{array}$ \\
\hline
\end{tabular}




\begin{tabular}{|c|c|c|}
\hline Design principle & Augmented reality & Virtual reality \\
\hline & $\begin{array}{l}\text { reflected in the power and direc- } \\
\text { tion of a golf swing. }\end{array}$ & $\begin{array}{l}\text { walking arounds a particular mu- } \\
\text { seum exhibit. }\end{array}$ \\
\hline Consistency & $\begin{array}{l}\text { Consistency refers to having simi- } \\
\text { lar operations and elements for } \\
\text { achieving similar tasks to provide } \\
\text { the user with a smooth, clean expe- } \\
\text { rience. Thus, for example, text la- } \\
\text { bels and text sizes should be con- } \\
\text { sistent throughout the AR applica- } \\
\text { tion. }\end{array}$ & $\begin{array}{l}\text { Visual elements in VR such as la- } \\
\text { bel should have a consistency of } \\
\text { appearance. Interaction should be } \\
\text { consistent e.g. if an object can be } \\
\text { selected via an air tap, make it also } \\
\text { selectable via a voice command } \\
\text { [6]. This not only provides con- } \\
\text { sistency but improved user acces- } \\
\text { sibility. }\end{array}$ \\
\hline Affordance & $\begin{array}{l}\text { Affordance refers to an attribute of } \\
\text { an object that allows people to } \\
\text { know how to use it e.g. the recycle } \\
\text { bin. While modern interfaces have } \\
\text { tended to remove the affordances, } \\
\text { it is important to ensure that it is } \\
\text { still clear what are clickable ele- } \\
\text { ments. Thus, UI elements should } \\
\text { be designed to mimic, to a reason- } \\
\text { able extent, the shape of real-world } \\
\text { objects (skeuomorphism). }\end{array}$ & $\begin{array}{l}\text { Familiar environments and objects } \\
\text { help new VR users feel more com- } \\
\text { fortable and present in the virtual } \\
\text { space. It also gives a feeling of } \\
\text { control by associating familiar } \\
\text { knowledge and behaviours with } \\
\text { objects and their corresponding } \\
\text { physical reactions. For example, to } \\
\text { open a door, the user might pick up } \\
\text { a key put it in the lock and turn it } \\
\text { as they would in the real world. }\end{array}$ \\
\hline
\end{tabular}

\section{Case study: Workshops on AR and VR prototyping}

A workshop was run for 36 master's students on a design course. It was divided into two parts. In part 1, students were required to develop an application in augmented reality. They were shown an idea for low-fidelity prototyping using a cardboard frame as a screen. As the user, holding the cardboard frame, moved it around the scene, others held out tabs of paper attached to short sticks with additional information.

Users learned the technique of bodystorming with paper annotations and used them easily. Some comments made are shown in Table 3:

Table 3. Comments from students regarding Augmented Reality

\begin{tabular}{ll}
\hline \multicolumn{1}{c}{ Positive comments } & \multicolumn{1}{c}{ Problems of suggested improvements } \\
\hline $\begin{array}{l}\text { We designed a diet app to introduce snacks en- } \\
\text { ergy to users. it's a very fresh experience. }\end{array}$ & $\begin{array}{l}\text { User had issues with dimensions - hands not } \\
\text { big enough }\end{array}$ \\
\hline $\begin{array}{l}\text { We got the sense of how easy and cost effec- } \\
\text { tive can be AR prototyping with using simple } \\
\text { tools like post-it notes and wood sticks. We } \\
\text { have created AR navigation of the building } \\
\text { which was interesting. }\end{array}$ & $\begin{array}{l}\text { Problems: simulation object size / incomplete } \\
\text { user journey. }\end{array}$ \\
\hline $\begin{array}{l}\text { I've learned some ways to simulate AR experi- } \\
\text { ence in the real-world and it's pretty cool and } \\
\text { useful }\end{array}$ & $\begin{array}{l}\text { For interfaces that are far away, it is hard to } \\
\text { create big enough labels to read. }\end{array}$ \\
\hline $\begin{array}{l}\text { Easily and quickly created the prototype, there- } \\
\text { fore the experience. }\end{array}$ & $\begin{array}{l}\text { Problem might be that we don't know if it is } \\
\text { feasible. }\end{array}$ \\
\hline
\end{tabular}




\begin{tabular}{ll}
\hline $\begin{array}{l}\text { Learn: the journey can really be simulated with } \\
\text { diverse methods. }\end{array}$ & $\begin{array}{l}\text { Provide technology which can lead to high fi- } \\
\text { delity period. }\end{array}$ \\
\hline $\begin{array}{l}\text { It's really fun to experience the journey of or- } \\
\text { dering food by AR. }\end{array}$ & $\begin{array}{l}\text { Spending more time on mocking up design } \\
\text { concepts. }\end{array}$ \\
\hline $\begin{array}{l}\text { Got to know how the context suitable for AR. } \\
\text { Worked out some ideas based on the AR. }\end{array}$ & $\begin{array}{l}\text { Seeing the workflow on AR/VR and what it } \\
\text { can do might be more useful. }\end{array}$ \\
\hline $\begin{array}{l}\text { I've learned that I don't need to use fancy and } \\
\text { expensive devices all the time. We can just use } \\
\text { simple papers or applications. }\end{array}$ & $\begin{array}{l}\text { Offer digital prototyping lessons e.g. Adobe } \\
\text { After effects }\end{array}$ \\
\hline $\begin{array}{l}\text { The people in my team were imaging different } \\
\text { things from our initial concept. So it's useful to } \\
\text { quickly compare our ideas in concrete. }\end{array}$ & $\begin{array}{l}\text { I would like to know more about techniques as- } \\
\text { pect. How to make idea become a reality. }\end{array}$ \\
\hline
\end{tabular}
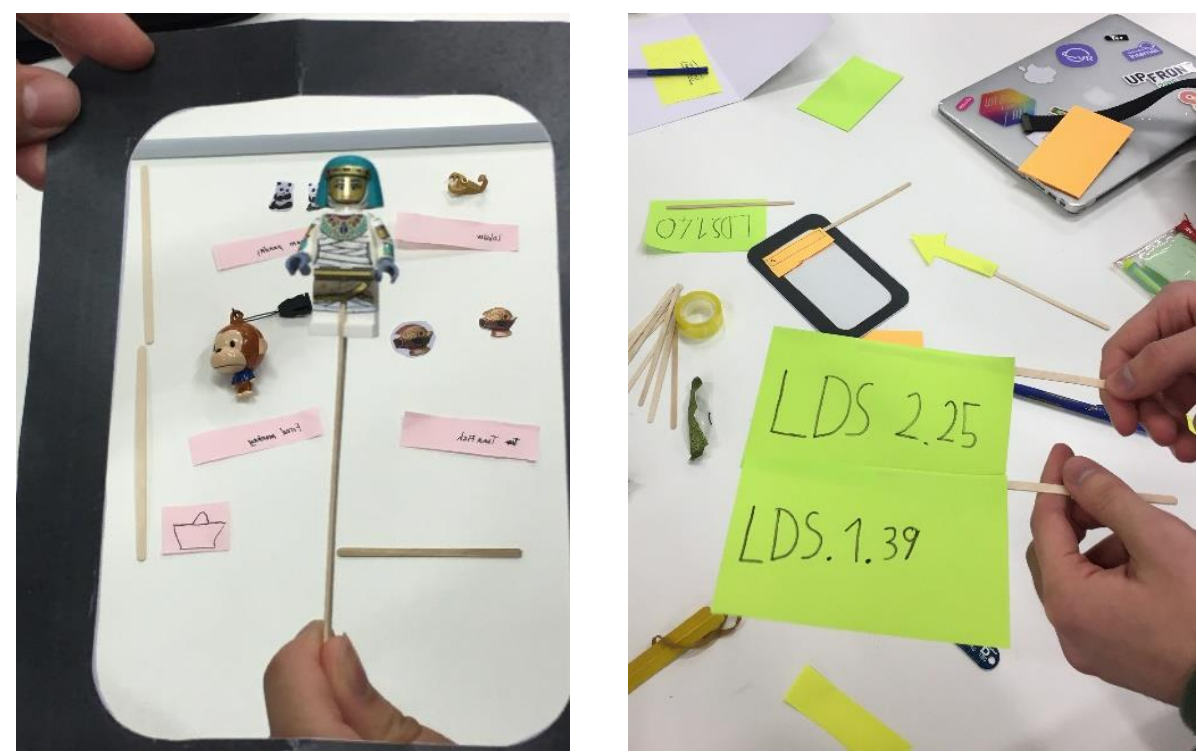

Fig. 2. Use of props to create AR effects within two prototypes (an augmented restaurant menu and a room finder app)

One problem that users faced was being able to line up the AR elements behind the cardboard frame with the object being annotated. Another was creating annotations that were a suitable scale for the frame without obscuring the object being viewed.

For the second part of the workshop, the participants were asked to translate their AR prototype into VR. Some comments from the exercise are shown in Table 4.

Table 4. Comments from students regarding Virtual Reality

\begin{tabular}{ll}
\hline \multicolumn{1}{c}{ Positive comments } & \multicolumn{1}{c}{ Problems of suggested improvements } \\
\hline $\begin{array}{l}\text { Had fun creating the user experience using } \\
\text { props, some big functions were missing due to } \\
\text { the lack of time. }\end{array}$ & $\begin{array}{l}\text { I don't know whether there should be a trigger.. } \\
\text { VRearable glasses to put the user into the }\end{array}$ \\
\hline $\begin{array}{l}\text { A little confused about perspective and trans- } \\
\text { ferring photos to stereoscopic version. }\end{array}$ & $\begin{array}{l}\text { I'm not good at painting... so I don't know how } \\
\text { to draw 3D objects into 2D pictures. }\end{array}$ \\
\hline
\end{tabular}




\begin{tabular}{ll}
\hline $\begin{array}{l}\text { Unsure at first. After seeing it demonstrated it } \\
\text { was finally clear. }\end{array}$ & $\begin{array}{l}\text { Have no idea how to transform AR wayfinding } \\
\text { to VR. }\end{array}$ \\
\hline $\begin{array}{l}\text { It was a very interesting experience to let me } \\
\text { practice and feel about the VR. }\end{array}$ & It wasn't as close [as I would like] to actual VR. \\
\hline $\begin{array}{l}\text { Useful, learned how the perspective will be } \\
\text { changed. }\end{array}$ & It's a bit hard to imagine it in the real world. \\
\hline $\begin{array}{l}\text { The difference was about the use of buttons. It } \\
\text { wasn't difficult to move from AR to VR. }\end{array}$ & $\begin{array}{l}\text { I would like to experience more devices or } \\
\text { [ways to prototype in VR] }\end{array}$ \\
\hline $\begin{array}{l}\text { It's good to quickly understand the application } \\
\text { of VR. But the time was short and limited to } \\
\text { gain more knowledge. }\end{array}$ & $\begin{array}{l}\text { For VR to design, we need a device such as a } \\
\text { VRet or 3D camera. }\end{array}$ \\
\hline $\begin{array}{l}\text { We can share the prototype with other people } \\
\text { to play with. }\end{array}$ & $\begin{array}{l}\text { For VR to design, we need a device such as a } \\
\text { VR headset or 3D camera. }\end{array}$ \\
\hline $\begin{array}{l}\text { Impressive and motivational. Learn lots of new } \\
\text { things. I now know how to design a virtual re- } \\
\text { ality prototype. Amazing. }\end{array}$ & $\begin{array}{l}\text { It was more difficult than augmented reality } \\
\text { because it is something very new. Wasn't sure } \\
\text { how to do it, how it works. }\end{array}$ \\
\hline $\begin{array}{l}\text { What's different is that the products will be } \\
\text { floating in the middle of the air for the user to } \\
\text { choose. It was very helpful for me to learn VR } \\
\text { prototyping. }\end{array}$ & $\begin{array}{l}\text { It needs a VR wearable device and something } \\
\end{array}$
\end{tabular}

Generally, the students felt positively towards the workshop in terms of learning how to construct low-fidelity prototypes for AR and VR (see Fig. 3)

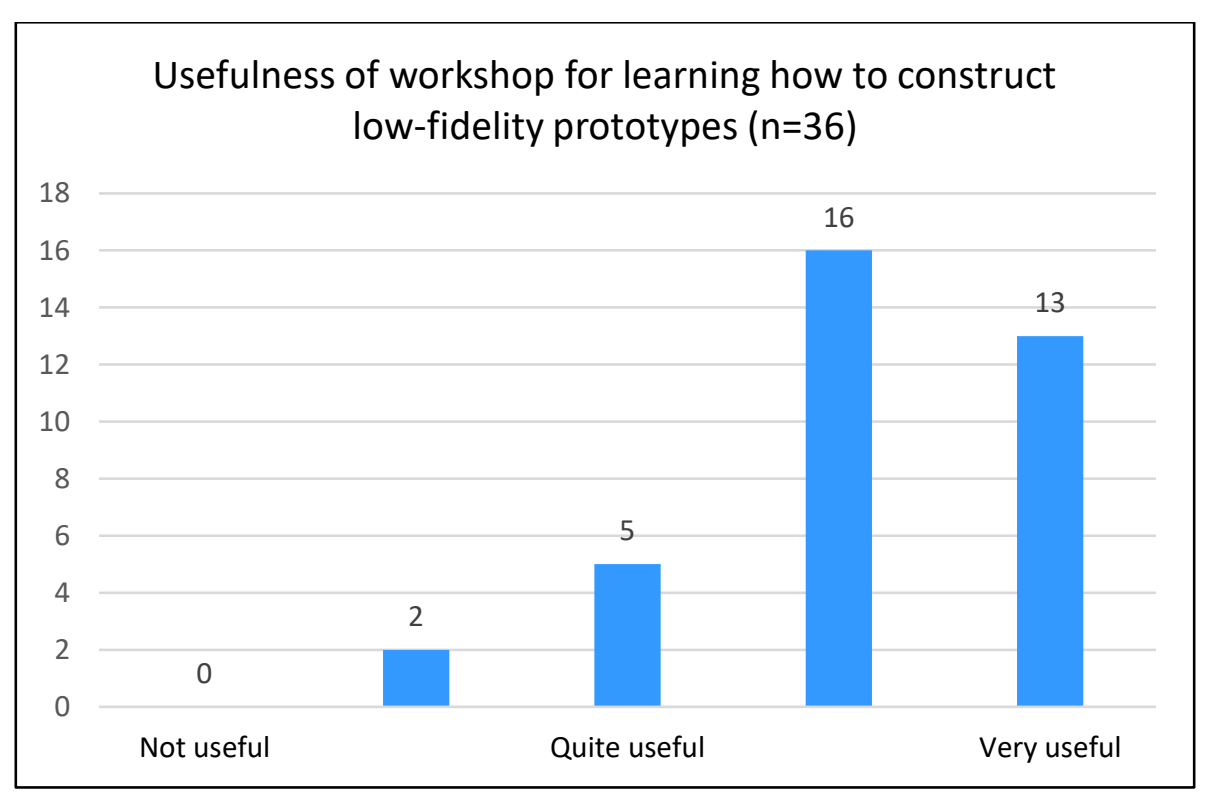

Fig 3. Usefulness ratings given to workshop 
Some of the key outcomes were that while students found the VR prototyping enjoyable, they felt they needed a structure similar to the AR session where the user was looking through the cardboard frame. A laser pointer was also available to use for indicating an item remotely (like an VR pointing device).

A second student workshop focused solely on VR prototyping was run where further techniques for rapid prototyping were tested. Working in groups, the 6 participants each created four scenes on large sheets of card for a chosen application (create a garden and Mars mission). They then navigated through the 'environment' by either wearing a cardboard set of Goggles or by manipulating a cardboard overlay with a viewport for viewing the scene. It was felt that both the goggles and the viewport were reasonably effective with the viewport being marginally preferred. Participant feedback on the workshop experience was generally positive. One comment was: "It was an interesting journey. I enjoyed the process of drawing scenarios and creating a story board. It is a challenge to make a vivid and contextual scenario".

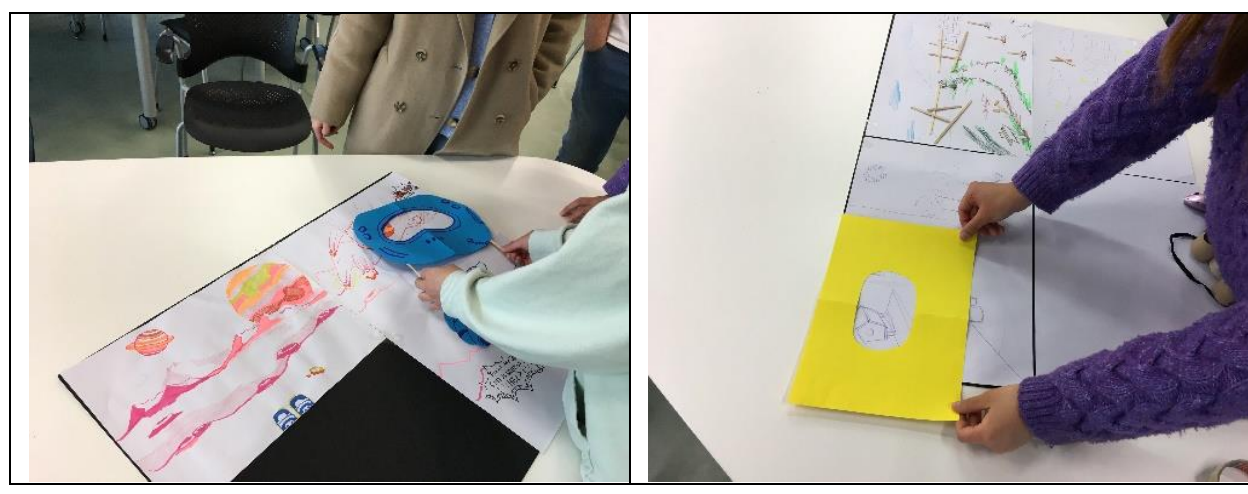

Fig. 4. Using 2D scenes with a cardboard mask with viewport to simulate virtual reality

\section{Conclusion}

This paper has considered how different user-centered methods can be used to develop the user experience for augmented and virtual reality applications. Yet they are not in themselves novel and could equally well be applied to traditional types of applications. The essential idea is that low-fidelity methods combined with a good imagination can be an efficient way to explore ideas and even develop the basic structure of an application and the user flows through it. They can also help to try and mimic the emotional experiences that it the design team hope to achieve with the final developed system. Of course, the development team will only be able to tell it the intended user experience is mirrored when the application is programmed using AR software or developed using a VR development kit and presented through the headset. However, low-fidelity techniques should enable to design team to save a lot of time an effort in designing an application that offers a usable design and an enjoyable user experience. 


\section{References}

1. Mobgen, Accenture Interactive: Low-fi prototyping: what, why and how? https://www.mobgen.com/low-fi-prototyping/, last accessed 2020/02/24.

2. ISO 9241-210 Human-centred design processes for interactive systems, Ergonomics of humansystem interaction, International Organization for Standardization, Geneva, Switzerland (1999, 2019)

3. Microsoft, case study expanding the design process for mixed reality, https://docs.microsoft.com/en-us/windows/mixed-reality/case-study-expanding-the-design-process-formixed-reality, last accessed 2020/02/24.

4. Jaime, S.: Rapid prototyping methods for AR \& VR, https://medium.com/@ oneStaci/vr-ar-prototyping-8e6d59cb260c (2107), last accessed 2020/02/24.

5. Thompson, A., Potter, L. E.: Taking the 'A' out of 'AR': play based low fidelity contextual prototyping of mobile augmented reality, CHI PLAY '18 Extended Abstracts: Proceedings of the 2018 Annual Symposium on Computer-Human Interaction in Play Companion Extended Abstracts, pp. 647-653 (2018).

6. Prototypr, Creating user flows with mixed reality, https://blog.prototypr.io/creating-user-flowsfor-mixed-reality-1986f8b85247, last accessed 2020/02/24.

7. Norman, D.: The Design of Everyday Things: Revised and Expanded Edition, Basic Books, New York (2013).

8. Purwar, S.: Designing User Experience for Virtual Reality (VR) applications, https://uxplanet.org/designing-user-experience-for-virtual-reality-vr-applications-fc8e4faadd 96 , last accessed 2020/02/24. 